Research Article, Issue 1
Analytical Methods in Environmental Chemistry Journal
AMECJ

\title{
Environmental Health Analysis: Assessing the emission levels of benzene from the fuel tanks doors of the vehicles in Tehran city
}

\author{
Seyed Alireza Hajiseyed Mirzahosseinia,* \\ ${ }^{a}$ Department of Environmental Engineering, Faculty of Natural Resources and Environment, Science and Research Branch, Islamic Azad University, \\ Tehran, Iran
}

A R T I C L E I N F O:

Received 16 Nov 2019

Revised form12 Feb 2019

Accepted 30 Feb 2019

Available online 19 Mar 2019

Keywords:

Volatile Organic Compounds

Benzene emission

PhoCheck

Domestic cars

Analysis of benzene in Air

\begin{abstract}
A B S T R A C T
In this study, 350 vehicles in 20 different models were examined in one of Tehran's Automobile Technical Inspection Centers. The laboratory tests indicate that longtime exposure to benzene has destructive effects on the blood cells, especially the bone-marrow cells. The concentration levels of benzene caused by the emission of gasoline vapors from fuel tanks doors were measured by PhoCheck EX5000 during a 5 to 15 -minute interval for each car. The results indicate that the concentration of benzene caused by the emission of gasoline vapors from the fuel tanks door of the domestic cars was 10 times higher than the imported cars. In most of the imported cars, the amount of benzene in the three measured areas was negligible. This is due to the use of new technology and adaptation of strict environmental standards by the manufacturing country.
\end{abstract}

\section{Introduction}

In recent decades, the various pollutants are being detected in urban areas which are mainly caused by fossil fuel components. They include a wide spectrum of hydrocarbons. The aromatic hydrocarbons are either bio-chemically or biologically active and are potentially carcinogenic or are by-products of benzene. Many of the recent

\footnotetext{
* Corresponding Author.

E-mail: mirzahosseini@gmail.com

DOI: https://doi.org/10.24200/amecj.v2.i01.47
}

researches indicate the adverse effects of benzene on human health. Although VOCs are quite important, there have been few studies conducted in this regard in Tehran metropolitan [1-2]. The main emphasis has been on measurement, monitoring and control of VOCs in the last 10 years. The concentration of hydrocarbons in Tehran is much higher than other cities in the world (the benzene and butadiene $1 \& 3$ levels in Tehran are 10 and 18 times the permissible standards). [2].

Amongst the hydrocarbons, benzene due 
to its carcinogenic effects has an especial importance. The main sources of benzene emission in Tehran are the motor vehicles and the gas stations (due to the evaporation of fuel and lack of the fume control system). Majority of the vehicles in Tehran are run on gasoline and regrettably, their consumed gasoline has high benzene content (about $5 \%$ of the weight). Moreover, most of the automobiles manufactured domestically lack environmental standards. They can only attain Euro 2 Standard that was ratified in 1996. This is done through modifications in their appearance and the pollution control systems. Meanwhile, the production lines of reference companies like Peugeot 405 and Kia Pride have stopped abroad more than a decade ago. It is important to point out that the two major auto manufactures of Iran, namely SAIPA and Iran Khodro assemble the decade-old products of the aforesaid companies. [2]

Various studies are conducted on the effect of domestically produced fuel and vehicles' quality on air pollution. Similar researches are conducted in Brazil and Pakistan.[ 3-4]. Batterman in 2005 studied the amount of benzene emitted from the fuel tank. Based on his measurements, the average level of benzene emission was 2 milligrams per hour. For old vehicles, this amount reached 62 milligrams per hour. In this study, the replacement of the gas cap and the washer of the fuel tank were regarded as measures to reduce the amount of evaporated fumes [5]. It is important to point out that the Iranian and international standard level of benzene in ambient air is $1.56 \mathrm{ppb}$ and in advanced countries like Japan is 0.69 ppb. For most countries in the world, the Euro 4 standard was used in 2005[6].

The laboratory tests indicate that longtime exposure to benzene has destructive effects on the blood cells, especially the bone-marrow cells. These effects cause the reduction in production of bone-marrow cells and anemia. The long term effect of benzene is leukemia. Environment Protection Agency (EPA) categorizes benzene in group A of carcinogenic substances. Also, the International Agency for Research on Cancer (IARC) refers to benzene as a carcinogenic substance for humans[7-9].

\section{Material and Methods}

In this research, the benzene concentration is measured by PhoCheck EX5000 equipment. This device is portable and with the aid of Photo Ionization Detector (PID) mechanism can measure the benzene concentration level with high precision ( $\pm 1 \mathrm{ppb})$. The PhoCheck takes samples from the gasoline fumes with the flow rate of 220 millimeters per minute. This device with its high precision (ppb level) samples the benzene through a portable laboratory chromatograph. It is important to point out that Krypton lamp of $10.6 \mathrm{eV}$ is used in this device. One of the most important advantages of this equipment is its approved technology to determine the benzene concentration with the accuracy of 1 ppb to $10000 \mathrm{ppm}$ as well as its good performance in weathers ranging from -20 to 60 degrees[10].

In this study, 350 automobiles encompassing 20 models are examined in the Automobile Technical Inspection Center of Tehran. The benzene concentration due to the gasoline fume is measured at three important spots namely, the gas cap, muffler and inside the cabin during a period of 5 to 10 minutes (for each car). It 


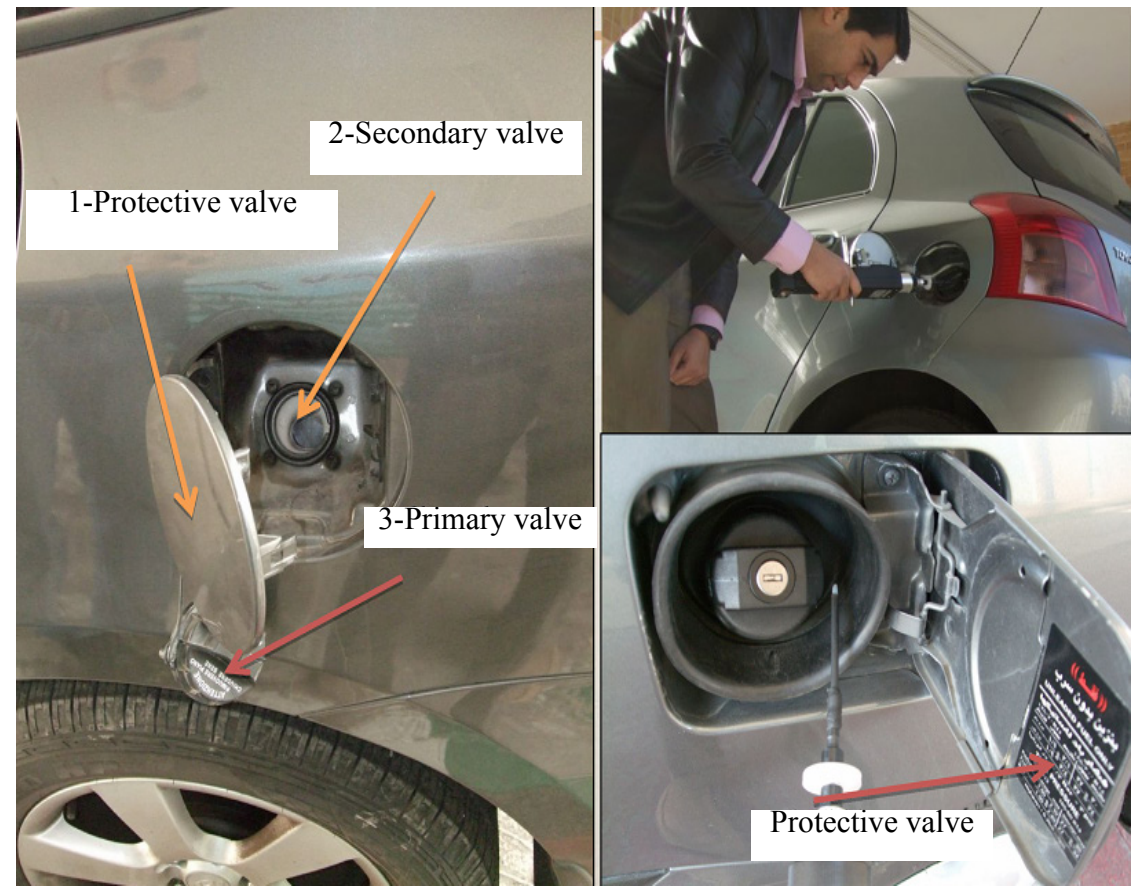

Fig. 1. Sampling method of the fuel tank, the protective valve, primary and secondary valves (if present)

is important to point out that all the cars were tested for the fume emission, after they received their certificate from the Technical Inspection Center. All the Iranian made cars are required to be inspected annually after the $2^{\text {nd }}$ years of production and obtain the certificate. For the ease of study, 350 automobiles were divided into two categories' of imported and domestic vehicles.

In most of the studied cars, there were three protective valves for the gas cap (except the Peugeot 206). The protective valve has a physical function without being in direct contact with the gasoline and its fumes. However, if the first valve (which is in direct contact with the gasoline and the fumes) fails, the leaked fumes would enter the small chamber of the protective valve for subsequent release to the atmosphere.

The second valve plays its role in controlling the fumes and the overflow of gasoline. In most of the domestically manufactured cars (except Renault L90), this valve does not exist. Figure1 illustrates the position of the three valves and the means to measure benzene. During measurement, the engine is off and only the protective valve is open. Since the valve in Peugeot 206 is in one piece, only the space between the chassis and the gas cap is sampled. Unfortunately, in Peugeot 405 with carburetor, the

Table 1. The minimum, maximum and average concentration levels of benzene in 12 models of imported cars (the amounts are in ppb)

\begin{tabular}{lllllllllllll}
\hline Car Type & Hyundai & Nissan & Mazda & Gol & Kia & Zantia & Roniz & Cielo & Toyota & Prado & Benz & BMW \\
\hline Average & 0.03 & 0.98 & 0.21 & 0.86 & 0.16 & 0.34 & 2.34 & 0.57 & 0.68 & 0.12 & 0.15 & 0.1 \\
Max & 0.397 & 3.6 & 0.83 & 9.4 & 0.98 & 0.97 & 6.9 & 2.3 & 4.3 & 0.3 & 0.73 & 0.7 \\
Min & 0 & 0 & 0 & 0.82 & 0 & 0 & 0 & 0 & 0 & 0 & 0 & 0 \\
\hline
\end{tabular}


Table 2. The minimum, maximum and average concentration of benzene in domestic vehicles in 8 models (measured in $\mathrm{ppb}$ )

\begin{tabular}{lllllllll}
\hline Car Type & Tondar 90 & Paykan & Pars & 405 & 206 & Pride & Samand & Rio \\
\hline Average & 6.59 & 76.21 & 26.21 & 6.83 & 3.09 & 43.86 & 3.94 & 0.43 \\
Max & 38.2 & 296 & 151 & 59.6 & 51.5 & 295 & 7.35 & 1.95 \\
Min & 0 & 2.06 & 0 & 0 & 0 & 0 & 0 & 0 \\
\hline
\end{tabular}

gasoline fume was emitted from other parts of the car (underneath the fuel tank and the engine).

\section{Results and Discussion}

\section{1. concentration levels of benzene in 12 models}

\section{of imported cars}

The imported automobiles consisted of 116 vehicles from 12 company models. The results indicated that Gol (manufactured by Volkswagen) has the highest amount of benzene leakage from the gas cap. The average concentration of benzene in this group is $86.5 \mathrm{ppb}$. The lowest concentrations of benzene were detected in Hyundai, Kia, Mercedes Benz, BMW and Prado in amounts of $0.03 \mathrm{ppb}, 0.16 \mathrm{ppb}, 0.15 \mathrm{ppb}, 0.01 \mathrm{ppb}$ and 0.12 ppb, respectively. It is important to point out that Mercedes Benz and BMW models in 70 percent of the cases registered zero concentrations (the best condition). With respect to the fuel type (super and regular gasoline), 28 percent of the samples used were super unleaded gasoline (Octane number of 95 ) and 72 percent were regular unleaded gasoline (Octane number of 87). The average age of the vehicles in this classification was 3.8 years. About 65 percent of the sampled automobiles had less than 3 years of operation.

In Table (1), the minimum, maximum and average concentrations of benzene are provided. The minimum amounts of measured benzene in all models, except Gol, were zero. Gol model showed the highest benzene leakage from the gas tank.

It is important to point out that the most important reasons for the emission of benzene fumes in this category are lack of tightening the gas cap and over fueling (pumping too much gasoline into the fuel tank). The average concentration of emitted benzene from the fuel tank of the imported vehicles (116 automobiles) is $0.96 \mathrm{ppb}$.

\section{2. concentration levels of benzene in 8 models of domestic vehicles}

In the domestically manufactured auto category, a total of 234 cars in eight various models are investigated. Based on the results, Paykan and Pride show the highest leakage of benzene from the gas cap with the average benzene concentrations of 21.76 and $86.43 \mathrm{ppb}$, respectively. It should be pointed out that the average age of the examined automobiles was 4.8 years, where $65 \%$ of the sampled cars had less than 5 years of age. In regard to the fuel type consumption, the super and regular gasoline was used $22.2 \%$ and $77.8 \%$, respectively. The lowest concentrations of benzene are detected in Rio and Peugeot 206 as 0.43 and 3.09 ppb, respectively. It is important to mention that Peugeot 206 has registered zero concentration in over 35\% of its samples. Table 2 presents the minimum, maximum and average benzene concentration.

It reveals that the minimum benzene concentration in all models except Paykan was zero. The primary 
reasons for the emission of benzene fumes in this group are technical defects of the primary gas cap, lack of the secondary gas cap, over fueling and lack of canister system. Also, about $9 \%$ of the domesticated vehicles run on carburetors whose average benzene concentration (in 234 automobiles) is $20.89 \mathrm{ppb}$. As it is shown in Table $2-2$, the emission from the gas caps goes up as the age of the vehicle increases.

\section{Conclusions}

Majority of the domestic cars emit high levels of benzene from the gas cap, muffler and the gas tank. The best and worst domestically manufactured automobiles are Peugeot 206 and Pride, respectively. The most prominent reasons for high concentration of benzene in this category are the lack of appropriate catalyst system, technical defects in fuel system, and fuel leakage from the gas cap. Amongst the imported car category, Kia and Hyundai groups have the lowest emission of benzene. In most of the imported cars, the amount of benzene in the three measured areas was negligible. This is due to the use of new technology and adaptation of strict environmental standards by the manufacturing country.

Based on the research results, the amount of benzene concentration due to the leakage of gasoline fumes from the gas cap in domestic cars is approximately ten times higher than the imported cars. In Pride models, the level of gasoline fume emission is considerable and the benzene concentration is 15 times higher than Peugeot 206. Moreover, the average benzene concentration from the emission of gasoline fumes from the gas cap of the imported cars is less than 6 ppb. However, this number for much of domestic cars was higher than $6 \mathrm{ppb}$. Pride is identified as the most polluting vehicle in the domestic car category. The research results indicate that the annual inspect of the gas tank, periodical replacement of washer, and modification of the gas cap system in the domestic cars have significant impact on the reduction of gasoline fumes.

\section{References}

[1] A. Karbasi, S. Khoramnezhadian, S. Asemi Zavareh, Gh, Pejman Sani, Determination of the emission rate and modeling of benzene dispersion due to surface evaporation from an oil pit, J. Air Pollut. Health, 3 , 3 (2018) 155-166.

[2] F. Atabi, SAH. Mirzahosseini, GIS-based assessment of cancer risk due to benzene in Tehran ambient air, Int. J. Occup. Med. Environ. Health, 26, 5 (2013) 770-779.

[3] N.V. Heeb, A. M. Forss, C. Bach, Fast and quantitative measurement of benzene, toluene and $\mathrm{C} 2$ benzene's in an automotive exhaust during tran-sient engine operation with and without catalytic exhaust treatment, Atmos. Environ, 33 (1999) 205-215.

[4] GT. Johnson, SC. Harbison, JD. McCluskey, RD. Harbison, Characterization of cancer risk from airborne benzene exposure. Regul. Toxicol. Pharm; 55 (2009) 361-366

[5] S. Batterman, G. Hatzivasilis, C. Jia, Concentrations and emissions of gasoline and other vapors from residential vehicle garages. Atm. Environ., 40 (2006) 1828-1844.

[6] H. Kajihara, S. Ishizuka, A. Fushimi, A. Masuda, J. Nakanishi, Population risk assessment of ambient benzene and evaluation of benzene regulation in gasoline in Japan. Environ. Eng. Policy, 2 (2000) $1-9$.

[7] Agency for Toxic Substances and Disease Registry (ATSDR), Toxicological Profile for Benzene(Draft). 
U.S. Public Health Service, U.S. Department of Health and Human Services, Atlanta, GA. (1997).

[8] S. Wilbur, ATSDR evaluation of potential for human exposure to benzene, Toxicol. Ind. Health, 24 (2008) 399-442.

[9] Department of the Environment and Heritage, Technical Report No.6: BTEX Personal Exposure Monitoring in Four Cities in Australia, Published by Environment Australia, (2003).

[10] PhoCheck Instrument, user manual V2.6, Ion Science Company(ISC), 2012. http://www. ionscience.com/products/phocheck-plus-handheldvoc-gas-detector\#downloads, 2012 